\title{
Em busca da clarineta perdida: conexão com a performance no reencontro com meus instrumentos
}

\author{
Ricardo Dourado Freire \\ Universidade de Brasília \\ freireri@unb.br
}

\begin{abstract}
Resumo: Este artigo é um relato de experiência sobre os procedimentos de divulgação pública de um processo de coleta de dados sobre performance musical. Este processo de pesquisa aconteceu em decorrência das restrições impostas pela pandemia do COVID-19, quando os protocolos de pesquisa estão sendo mediados por dinâmicas relacionadas tanto com a produção de vídeos quanto por dinâmicas de interação com mídias sociais. A convergência de métodos de pesquisa, produção artística e divulgação na internet criou um novo ambiente para realização de investigações artísticas. O projeto de pesquisa foi estabelecido em três etapas: 1) Definição do projeto de performance, 2) Produção de vídeos para internet, e 3) Elaboração de estratégias de divulgação em mídias sociais. O projeto Desafio com 15 clarinetas foi realizado em novembro de 2020, com pré-produção entre agosto e outubro, produção e publicação dos vídeos, entre 1 e 20 de novembro, nas plataformas Facebook, Instagram e Youtube. O projeto consistiu na gravação em vídeo da peça Hommage à Strauss, de Béla Kovács, com 15 configurações de instrumento, boquilha e palheta. O propósito desta experiência foi a preparação e divulgação de uma performance musical nas mídias sociais explorando as possibilidades atuais de elaboração de conteúdo, produção e divulgação.
\end{abstract}

Palavras-chave: Clarineta, Pesquisa em Performance, Produção Vídeos, Mídias sociais.

\section{Looking for the hidden clarinet: connection with music performance through practice with many instruments}

\begin{abstract}
Research in music performance and investigations in performance pedagogy aim to prepare musicians for public presentations. Music performance could be done live or recorded. The pandemic ceased public performances and recording sessions in studios were canceled. The only option for music performance was self-production projects to be streamed through the internet and social media. This article is an experience report based on the process of data collection about clarinet performance. The isolation due to COVID-19 imposed a reality in which I need to be with my clarinets and myself. It create an opportunity to research the voice inside different set-ups of instruments, mouthpieces and reeds. The objective was to record Hommage à R. Strauss by Béla Kovács, with 15 combinations of clarinets. The proposed consisted of three different projects: 1) Music performance project, 2) Video production project and 3) Social media project. The report shows what was necessary to organize and execute each project and how the combination of projects needed to work in order to promote music performance during the pandemic.
\end{abstract}

Keywords: Clarinet, Music Performance, Music Production, Social Media. 
ANEDOTA DE MÚSICO:

Quantos clarinetistas são necessários para trocar uma lâmpada?

- Somente um!

- Certeza?

- Sim, mas você precisa entregar a ele uma caixa com 100 lâmpadas e esperar que ele teste todas, até encontrar uma lâmpada com a luminosidade perfeita. (AUTOR DESCONHECIDO).

\section{Introdução}

O momento de pandemia não está para piadas, mas a anedota de músico ilustra, com humor e ironia, um aspecto central da identidade do clarinetista: o fascínio pela exploração de materiais que podem auxiliar na performance do instrumento. É um desafio diário, que se inicia com a busca por uma palheta perfeita ou mesmo imperfeita, e resulta em uma curiosidade para conhecer variedades de instrumentos, boquilhas, abraçadeiras, barrilhetes e campanas. Meu professor de clarineta, Luiz Gonzaga Carneiro (1928-2007), dizia que estava sempre à procura de uma boquilha que tocasse sozinha, mas nunca a encontrou. Como o voo de Ícaro em direção ao sol, clarinetistas estão sempre fascinados pelo inatingível, sendo que instrumentos e acessórios são as asas que os impulsionam nesta busca pela constante superação artística.

O período de isolamento social e a suspensão de todas as atividades musicais presenciais limitou um aspecto essencial da performance musical: a interação com o público e com outros músicos. Foram cancelados concertos, recitais, festivais, cursos, ensaios, aulas, rodas de choro, festas, comemorações, viagens, planos e sonhos. Tudo parado e sem perspectiva de retorno a curto, médio ou longo prazo. Uma solução imediata para as restrições de contato social foram eventos online destinados a suprir as interações sociais limitadas pelo distanciamento social. Outra solução foi resgatar projetos de pedagogia da performance que haviam sido iniciados e não foram finalizados.

A solidão imposta exigiu a convivência com a realidade da minha própria casa, e descobri que em casa eu não estava sozinho, estava acompanhado de vários instrumentos musicais, principalmente de clarinetas. As experiências durante a pandemia não ocorreram de maneira planejada ou intencional. As interações mediadas pelas novas tecnologias nas redes sociais com familiares, amigos e conhecidos se tornaram estímulos para conhecer melhor a linguagem atual da internet. A convivência remota com lives, reuniões, mensagens, posts, e-mails, criou um ambiente de interações, com demandas de 
novas aprendizagens e novas maneiras de abordar a pesquisa em performance musical. Neste momento começou a ser delineado um projeto de pesquisa que foi estabelecido em três etapas distintas de maneira não-linear: 1) Definição de um projeto de performance; 2) Capacitação em produção visual para internet; 3) Elaboração de estratégias de divulgação em mídias sociais.

Este artigo é um relato de experiência sobre os procedimentos de divulgação pública de um processo de coleta de dados sobre performance musical. O processo de pesquisa aconteceu em decorrência das restrições impostas pela pandemia do COVID19, quando os protocolos de pesquisa passaram a ser mediados por dinâmicas relacionadas tanto com a produção de vídeos quanto por dinâmicas de interação com mídias sociais. A convergência de métodos de pesquisa, produção artística e divulgação na internet criou um novo ambiente para realização de investigações artísticas. $O$ isolamento exigiu a ampliação dos conhecimentos do pesquisador para lidar com as demandas de produção de vídeos e também as dinâmicas de divulgação em mídias sociais.

\section{Pesquisa em Performance Musical}

A pesquisa em performance musical pode ser realizada em contextos públicos de performance ou em contextos laboratoriais. Em ambos os casos existe a interação do pesquisador com os sujeitos da pesquisa, mas com a pandemia o contato entre pesquisador e sujeitos ficou limitada e tornou-se necessário buscar novas maneiras de realizar pesquisas em performance. Uma opção foi o pesquisador atuar como sujeito da sua própria investigação, isolado de contatos pessoais, e refém dos seus próprios recursos metodológicos.

A pandemia exigiu a convivência com o próprio espaço de isolamento. Neste período, dediquei-me a reorganização dos instrumentos e do espaço de trabalho domiciliar. O prolongamento da pandemia permitiu a retomada de antigos projetos, principalmente um projeto de pedagogia da performance sobre afinação. A pedagogia da clarineta está baseada na elaboração de exercícios técnicos e métodos realizados por clarinetistas. A abordagem francesa do Conservatório de Paris incentivou que cada professor de instrumento elaborasse métodos e estudos que se tornaram a base do 
desenvolvimento musical de cada instrumento (HOLOMAN, 2018). No caso dos clarinetistas, foram escritos métodos por C. Rose, H. Klosé, P. Jeanjean, A. Perier e U. Delecluse que são usados até hoje (GRELLIER, 2020).

A prática constituía na performance de quatro exercícios elaborados para o ajuste da afinação baseados em pesquisas anteriores de Freire (2016a, 2016b e 2017). Cada exercício deveria ser tocado com auxílio de um aplicativo de geração de notas musicais para produção de notas de referência. A partir de uma nota de referência, seriam explorados: 1) série harmônica, 2) série sub-harmônica, 3) intervalos descendentes e a identificação de harmônicos comuns e 4) notas resultantes.

O estudo de afinação exige a articulação entre percepção musical e ajuste técnico durante a performance. No caso da clarineta, existe o ajuste realizado com os músculos orbiculares e na manipulação do trato vocal que inclui principalmente a movimentação da língua e o posicionamento da laringe durante a performance. O controle muscular da face e do trato vocal possibilitam a flexibilidade necessária para a realização dos ajustes de afinação necessários durante a performance musical.

A elaboração de exercícios técnicos com objetivos específicos pode estar situada no campo da Pedagogia da performance musical, conforme definido por Ray:

\begin{abstract}
Pedagogia da Performance Musical é um campo de conhecimento que emerge da relação dialética entre educação e conhementos musicais, fundamentado nas teorias e práticas formadoras do músico que necessariamente atua em público com a expectativa de estar em público em sua atividade principal (RAY, 2019, p. 27).
\end{abstract}

Após a elaboração da série de exercícios tornou-se necessário testá-los e avalia-los. Os exercícios foram realizados durante duas semanas, mas a simples repetição não oferecia elementos para análise de resultados. Ficou evidente a necessidade de um número maior de sujeitos, que no entanto, não estavam disponíveis. Uma opção para investigar as respostas de afinação durante o exercício foi a realização dos exercícios com Clarineta em Lá e com Clarineta em Dó, para criar novas situações de afinação, pois cada instrumento é diferente. Outra opção de investigação foi a performance dos exercícios com diferentes boquilhas, que também apresentavam características específicas de afinação, sendo que boquilhas europeias são construídas para performance com Lá $=442$ $\mathrm{Hz}$, enquanto boquilhas dos EUA estão projetadas para Lá $=440 \mathrm{~Hz}$. 
A opção de testar o exercício com mais de um instrumento criou uma situação de exploração na qual o mesmo performer realizava uma atividade em diversos contextos, sendo que o processo de afinação tinha que ser adaptado para cada configuração de instrumento e boquilha. A possibilidade de investigação em diferentes situações permitiu o teste e validação dos exercícios enquanto possibilidades de desenvolvimento da afinação. Os testes iniciais mostraram os exercícios, com diferentes instrumentos e boquilhas, exigiam diferentes adaptações da embocadura e trato vocal para efetuar os ajustes de afinação. No entanto, a autoavaliação é um elemento limitante para pesquisadores, sendo necessário a validação por pares e aplicação com diversos sujeitos que ofereçam dúvidas e sugestões para o aperfeiçoamento do material didático para posterior publicação.

A possibilidade de testar combinações de instrumentos e boquilhas resgatou uma curiosidade juvenil e reavivou memórias do processo de busca de instrumentos e boquilhas vivenciado durante o período de estudos de Mestrado e Doutorado na década de 1990. Os testes foram ampliados para uso de todos os instrumentos do acervo pessoal, mesmo aqueles que não estavam sendo tocados a vários. A questão central foi criar uma forma de avaliação pública que pudesse investigar a performance musical com vários instrumentos. Neste caso, uma opção seria a preparação de vídeos de performances musicais para divulgação na internet.

\section{Preparação de vídeos para mídias sociais}

A divulgação de produção artística apresentou uma dinâmica de transformações durante a pandemia. A necessidade de produção de vídeos transformou a maneira como as produções foram realizadas. Produções caseiras e amadoras, puderam ser aperfeiçoadas e o acesso a equipamentos, softwares e cursos online permitiram que o padrão de realização da produção de vídeos atingisse um novo patamar de qualidade.

O processo de preparação de vídeos exige um conhecimento específico de produção audiovisual. A captura da imagem, gravação do áudio e edição de vídeo são habilidades separadas que exigem conhecimentos específicos para a preparação de vídeos para internet. $\mathrm{O}$ isolamento social, imposto pela pandemia, tornou a linguagem audiovisual 
para internet a principal forma de divulgação de trabalhos artísticos e vários músicos tiveram que aprender conceitos de produção de vídeos em cursos online.

Adaptação foi um aspecto importante do período de pandemia, e as formas de aprendizagem também precisaram ser adaptadas para uma nova forma de autodidatismo, o autodidata online. A partir da oferta de informações, torna-se possível que uma pessoa que queira aprender tenha acesso a uma grande quantidade de informações que precisam ser selecionadas e organizadas para promover a aprendizagem de conteúdo. No caso da produção de vídeo foram necessários conhecimentos sobre: a) conceitos de produção, 2) equipamento, 3) iluminação, 4) uso de software de edição de áudio, 5) uso de edição de vídeo e 6) gerenciamento de cores. A sequência de aprendizagens ocorreu de maneira não-linear, sendo que a necessidade de conhecimentos surgiu a partir de tentativas de gravações frustradas e na busca de um acabamento melhor para os vídeos produzidos.

O caminho para produção de vídeos para a internet foi procurar textos, vídeos e cursos disponíveis na própria internet. A rede de computadores, enquanto forma de comunicação e oferta de conteúdos digitais oferece os recursos para desenvolvimento de habilidades de produção de vídeos. Cursos e vídeos estão disponíveis em diversos formatos e propostas. A questão central foi organizar os recursos de aprendizagem para organizar o desenvolvimento das novas habilidades necessárias para a produção de vídeos.

O processo de gravação exigiu a definição de parâmetros de iluminação em uma sala que combinava luz natural e luz incandescente. O estudo de iluminação foi realizado durante a pandemia por meio de cursos em plataforma online internacional que indicou princípios básicos de iluminação e principalmente a necessidade da utilização de configurações manuais em Câmeras DSLR. Para a gravação foi utilizada uma Câmara CANON T3i, com microfone externo direcional conectado na câmera com distância de $2 \mathrm{~m}$ da fonte sonora e configurações de 24 quadros por segundo e ISO 1600. Os ajustes de foco foram realizados de maneira manual com lente definida para $18 \mathrm{~mm}$, sendo que a câmera foi mantida no mesmo local em cada uma das gravações.

A produção de um vídeo de alta qualidade técnica e artística necessita de um plano de divulgação para que o produto da performance possa ser amplamente divulgado e 
acessado nas redes sociais. Além da produção de qualidade, uma estratégia de divulgação torna-se essencial para que a performance musical encontre o seu público.

O processo de divulgação em mídias sociais exige paciência, disciplina e dedicação. O trabalho exige regularidade de publicações e sintonia na comunicação com o público alvo seja em uma abordagem pessoal, acadêmica ou comercial. O processo é muito parecido, pois está regulado pelos algoritmos que estabelecem as prioridades de divulgação entre os diversos usuários.

A dinâmica de interações das redes sociais tem características próprias e a promoção de conteúdos acontece no contexto de disputa de exposição de conteúdos orgânicos e conteúdos promovidos. Conteúdos orgânicos são textos, imagens ou vídeos colocados divulgados e compartilhados entre redes de amigos ou seguidores, neste caso os conteúdos não são pagos. Conteúdos promovidos são pagos e oferecidos para pessoas que tem um perfil de interesse específico. A convivência entre os dois tipos de conteúdo oferece um ambiente de disputa de espaços nos quais os conteúdos pessoais e orgânicos estão apresentados no mesmo contexto de conteúdos profissionais e pagos. A realidade mostra que conteúdos pessoais também precisam de estratégias de divulgação, o que não é diferente para a performance musical.

\section{Desafio 15 Clarinetas}

A investigação iniciada com o objetivo de testar exercícios de afinação foi ampliada para explorar a divulgação de performances musicais gravadas. Este objetivo criou uma questão de pesquisa: como avaliar a afinação da clarineta em situação de performance com diversas configurações de instrumento e boquilha no contexto das mídias sociais? $\mathrm{O}$ objetivo não era promover a comparação de marcas ou modelos de instrumentos/ boquilhas e sim oferecer possibilidades para que o público das mídias sociais pudesse perceber as diversas maneiras que um mesmo instrumentista pode realizar sua performance musical.

O projeto Desafio com 15 clarinetas foi realizado em Novembro de 2020, com préprodução entre agosto e outubro, produção e publicação, entre 1 e 20 de novembro, nas plataformas Facebook, Instagram e Youtube (Figura 2). A proposta consistiu em gravar a peça Hommage à Strauss, de Béla Kovács, empregando 15 instrumentos, boquilhas e 
palhetas diferentes. Dois instrumentos foram cedidos durante o projeto e no final foram realizadas dezesseis performances. Cada execução foi gravada e editada no mesmo dia, sendo que as publicações ocorreram de acordo com o calendário planejado para divulgação entre segunda e sexta-feira.

Figura 2 - Imagem de divulgação do Desafio com 15 Clarinetas

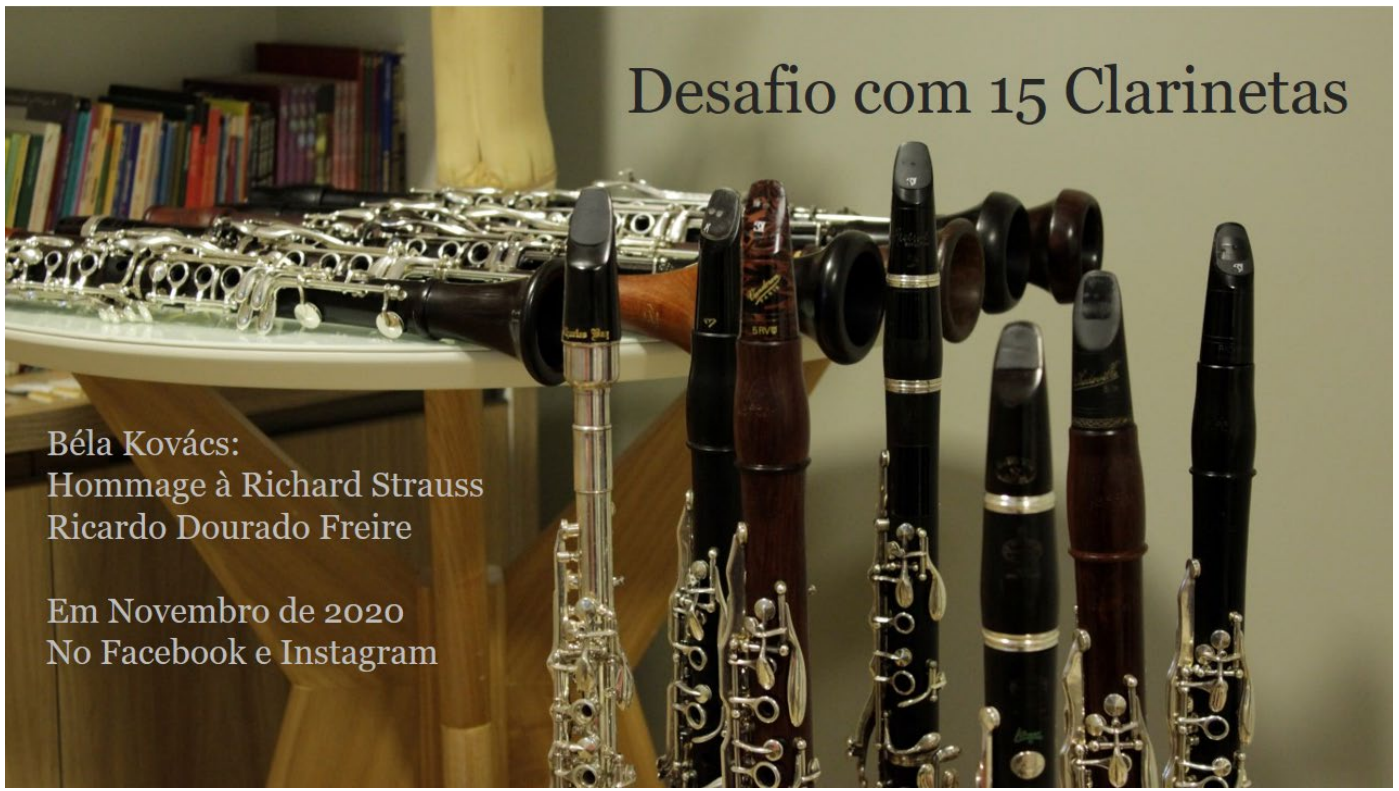

Produção do autor.

O acervo pessoal consistia de uma clarineta em Dó, sete clarinetas em Sib, duas clarinetas em Lá, um clarone em Sib, e uma clarineta de metal das marcas Luis Rossi (Chile), Royal Global (EUA), Devon Burgani (Brasil) e Selmer (França). Os instrumentos possuíam características específicas com utilização das madeiras grenadilla, rosewood, aroeira e pau-ferro. A configuração de diâmetros internos de cada instrumento também seguiam padrões de construção específicos conhecidos como câmara francesa $(14,85 \mathrm{~cm})$, câmara americana $(14,75 \mathrm{~cm})$ e câmara alemã $(14,65 \mathrm{~cm})$. Além das configurações originais, era possível fazer combinações entre o corpo principal de um instrumento com barrilhetes e campanas de outras marcas (Figura 1), sendo possível testar diversas combinações para cada instrumento. Um instrumento de grenadilla também poderia ser tocado com campana e barrilhete de rosewood, enquanto um instrumento de rosewood funcionou muito bem com campana e barrilhete de grenadilla. As diversas combinações permitiam novas descobertas e novas possibilidades de sonoridades e inicialmente foram definidas doze configurações de instrumentos em Sib. 


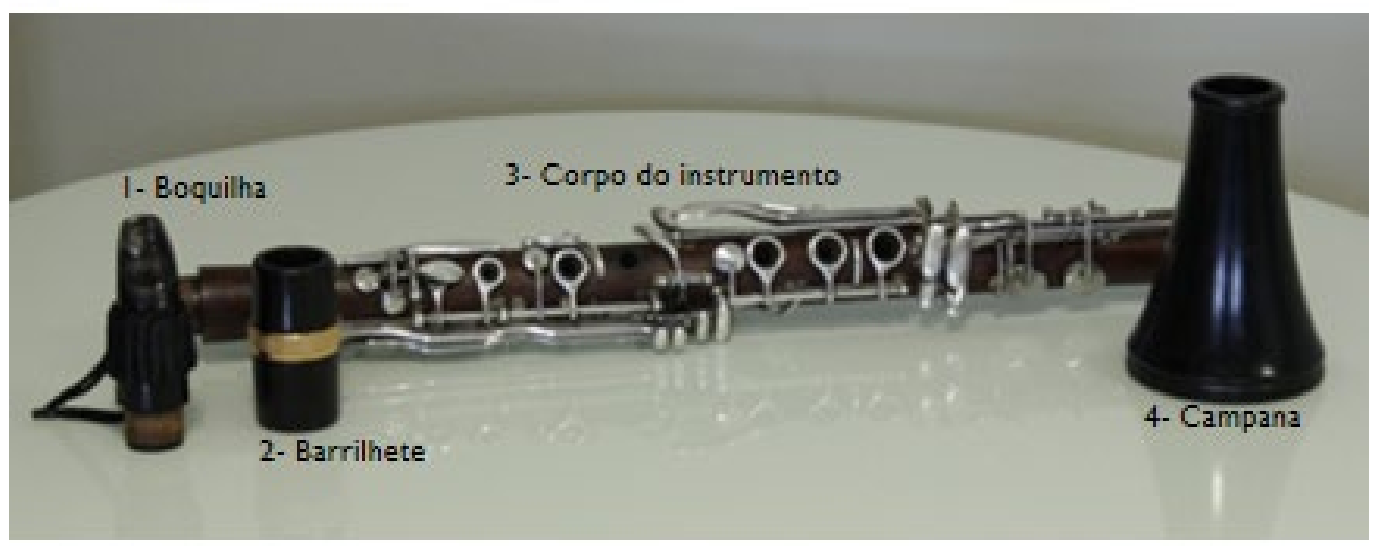

Durante o processo de performance com diversos instrumentos, houve a oportunidade de testar os instrumentos marca Buffet Grampom, do professor responsável pela minha formação: Luiz Gonzaga Carneiro. Os instrumentos estavam sob a guarda da clarinetista Eliana Costa e foram gentilmente cedidos pela viúva Eterna Castro. Durante o período de divulgação dos vídeos, o clarinetista Cícero Costa gentilmente ofereceu suas clarinetas Devon Burgani, de Conduru, e Yamaha 650, modelo amplamente utilizado em Bandas militares no Brasil. Ao final do processo, foram realizadas gravações com dez instrumentos utilizando dezesseis configurações diferentes (Tabela 1).

Tabela 1- Clarinetas e configurações de corpo do instrumento, campana e barrilhete

\begin{tabular}{l|l|l|l|l|l|l|l}
\hline \multicolumn{7}{c}{ CLARINETAS } \\
\hline VÍDEO & INSTRUMENTO & MADEIRA & CAMPANA & MADEIRA & BARRILHETE & MADEIRA & TAMANHO \\
\hline 1 & Buffet RC Prestige & Grenadilla & Buffet & Grenadilla & Buffet & Grenad. & 65 \\
\hline 2 & Rossi Americano & Grenadilla & Royal & Grenadilla & Royal & Grenad. & 62 \\
\hline 3 & Rossi Alemão & Rosewood & Rossi & Rosewood & Rossi & Rosewood & 62 \\
\hline 4 & Royal - Opera & Grenadilla & Royal & Grenadilla & Royal Polaris & Grenad. & 66 \\
\hline 5 & Rossi Francês & Grenadilla & Rossi & Grenadilla & Rossi & Grenad. & 62 \\
\hline 6 & DevonBurgani & Pau Ferro & Devon & Aroeira & Devon & Aroeira & 66 \\
\hline 7 & Rossi Francês & Rosewood & Rossi & F Rosewood & Rossi & Rosewood & 62 \\
\hline 8 & White Cleveland & Metal & & & & & \\
\hline 9 & Rossi Americano & Grenadilla & Rossi & W Rosewood & Rossi & Rosewood & 62 \\
\hline 10 & Buffet RC Prestige & Grenadilla & Devon & Aroeira & Devon & Aroeira & 66 \\
\hline 11 & Rossi Francês & Grenadilla & Rossi & W Rosewood & Rossi & Rosewood & 62 \\
\hline 12 & DevonBurgani & Curundu & Devon & Cunduru & Devon & Curundu & 65 \\
\hline
\end{tabular}




\begin{tabular}{l|l|l|l|l|l|l|l}
\hline 13 & Yamaha 650 & Grenadilla & Devon & Cunduru & Devon & Curundu & 65 \\
\hline 14 & Royal - Opera & Grenadilla & Kaçulinha & Pau-Brasil & Devon & Curundu & 66 \\
\hline 15 & DevonBurgani & Pau Ferro & Royal & Cocobolo & Royal & Cocobolo & 62 \\
\hline 16 & Rossi Francês & Rosewood & Rossi & Grenadilla & Rossi & Grenad. & 62 \\
\hline
\end{tabular}

Produção do autor.

Além do uso de diversos instrumentos, foram selecionadas dezesseis boquilhas de modelos e marcas distintas para criar um contexto de performance para cada instrumento. O design de uma boquilha define o grau de resistência oferecido para entrada de ar no instrumento (LAWSON, 1995). Além disso, as curvaturas internas e externas influenciam a forma como os músculos faciais iram configurar a embocadura do clarinetista. Uma boa boquilha funciona como um bom arco para o instrumentista de corda, permite que a energia mecânica se transforme em produção sonora. Desta maneira, boquilhas sempre exerceram fascínio para os clarinetistas e cada design tenta capturar e idealizar a subjetividade do clarinetista para produção de um ideal de sonoridade (Tabela 2).

Tabela 2- Configurações de boquilha, palheta e afinação.

\begin{tabular}{|c|c|c|c|c|}
\hline \multicolumn{5}{|c|}{ BOQUILHAS E PALHETAS } \\
\hline VÍDEO & BOQUILHA & PALHETA & No. & AFINAÇÃO \\
\hline 1 & James Pyne & Gonzalez & $33 / 4$ & 440 \\
\hline 2 & Dan Johnston 1998 & Vandoren V21 & $31 / 2+$ & 441 \\
\hline 3 & Vandoren BD7 & Marca Excel & $31 / 2$ & 441 \\
\hline 4 & Chedeville & Vandoren Trad. & 4 & 442 \\
\hline 5 & Richard Hawkins & Vandoren V21 & $31 / 2+$ & 442 \\
\hline 6 & Reserve EV10 & Gonzalez & $31 / 2$ & 442 \\
\hline 7 & Gennusa & Gonzalez CD & $31 / 4$ & 442 \\
\hline 8 & BD 513 & Reserve & $31 / 2$ & 443 \\
\hline 9 & Royal USA & Rico Reserve & $31 / 2$ & 441 \\
\hline 10 & Dan Johnston 2008 H3 & Reserve & $31 / 2+$ & 441 \\
\hline 11 & Charles Bay & Marca Excel & $31 / 2$ & 441 \\
\hline 12 & Reserve X10 & Gran Concert & 4 & 441,5 \\
\hline 13 & Dan Johnston 2008 H3+ & Marca Tradition & 3 & 442 \\
\hline 14 & Reserve X5 & Glotin & $31 / 2$ & 442 \\
\hline 15 & Vandoren M30D & Vandoren Black- German & 4 & 441 \\
\hline 16 & Vandoren 5RV & Vandoren 56 Rue lepic & $31 / 2$ & 441 \\
\hline
\end{tabular}

Produção do autor. 
Um acessório fundamental para a produção sonora da clarineta é a palheta de Arundo Donax, elemento que produz a vibração acústica necessária para a produção sonora da clarineta (ALMEIDA et al, 2013). A cana de bambu está presa a uma superfície plana da boquilha e imobilizada por uma abraçadeira que promove a estabilidade para $o$ efeito vibratório da palheta. Foram utilizadas dezesseis palhetas diferentes, de marcas e graus de resistência específicos, sendo que cada palheta foi escolhida de acordo com as características da boquilha escolhida para performance.

Cada configuração de instrumento, boquilha e palheta exigiu um período de adaptação do clarinetista. $\mathrm{O}$ primeiro aspecto de adaptação foi a definição da referência de afinação para cada configuração utilizada. A partir da afinação padrão de cada configuração, foi possível identificar os ajustes necessários para determinadas notas e também observar as tendências de afinação dos registros de cada configuração. Após definir a referência de afinação, foram realizados os exercícios de afinação elaborados anteriormente. O conjunto de exercícios funcionou como "aquecimento", ou seja, atividade de preparação muscular para a performance musical e atuaram na adaptação da musculatura facial e do trato vocal do clarinetista antes das gravações.

As gravações foram realizadas em 17 sessões, sendo que a primeira sessão foi uma sessão piloto para ajuste das configurações de iluminação, gravação em vídeo, enquadramento, volume de gravação e foco. Após a definição, as gravações foram realizadas com um instrumento por dia, para manter as mesmas condições de preparação e realização em cada sessão. As sessões ocorreram com gravação da peça para clarineta solo Hommage à R. Strauss, de Béla Kovács, em duas partes: Sessão 1 (p. 25-26) e Sessão 2 (p. 27-28) (KOVÁCS, 1996). Após a gravação de cada uma das partes, o vídeo foi editado para conexão das partes e foram necessárias movimentações de câmera e uso de recursos de reenquadramento para que a visualização do vídeo estivesse de acordo com os padrões de produção atuais.

As gravações foram disponibilizadas na plataforma YouTube, no endereço https://www.youtube.com/channel/UCjs-poN86eovRVc2pS1Cb5Q. Os arquivos disponibilizados no canal particular do YouTube foram divulgados na plataforma Facebook, por meio de link, e um arquivo separado foi disponibilizado na plataforma 
Instagram. Cada plataforma apresenta características e formas de interação específicas e cabe ao promotor de conteúdos explorar os públicos de cada formato. O YouTube se caracteriza como repositório de vídeos e pode ser divulgado por meio do compartilhamento de links dos vídeos por meio de e-mail, Whatsapp ou Facebook.

O processo de preparação e gravação de 16 performances para divulgação tornouse um procedimento de coleta de dados. Foi criada uma situação controle, no qual os parâmetros de gravação foram mantidos constantes, o material gravado foi o mesmo, o instrumentista foi o mesmo, a proposta artística foi a mesma. A proposta de realização com diversas configurações ofereceu uma nova forma de realizar pesquisa em tempos de pandemia. O objeto de investigação público, no qual o público de mídias sociais avalia e realiza suas próprias conclusões.

O pesquisador se tornou o sujeito principal de sua própria investigação e disponibilizou publicamente sua experiência de performance. Neste caso, o projeto tornou-se uma pesquisa em andamento, pois os dados estão disponibilizados para análise e avaliação do próprio pesquisador ou de outros pesquisadores. A coleta de dados pode ser submetida para análise de um grupo de focal, outros pesquisadores ou avaliação livre dos participantes da rede.

O objeto de investigação, no entanto, pode ser abordado de diversas maneiras e procedimentos de análise que podem seguir objetivos específicos. O propósito desta experiência foi a preparação e divulgação de uma performance musical na busca na exploração que existe no processo atual de elaboração de conteúdo, produção e divulgação.

Neste relato de experiência, o foco foi descrever o processo de adaptação da performance musical, e também da pesquisa em performance musical, no contexto de interações realizadas por meio das mídias digitais. O processo de preparação da performance com diversos instrumentos criou dificuldades similares a condições de performance em diversos ambientes musicais. No caso dos instrumentos, foi necessário um período de adaptação para cada instrumento, e a preparação para lidar com diferentes condições de performance. A gravação em vídeo cria uma situação de pressão por resultados em tempo real. A necessidade de publicação do material coloca em evidência 
o resultado artístico da performance musical e sua publicidade expõe as qualidades e defeitos do performer. A avaliação torna-se pública e a coleta de dados pode ser realizada a partir das percepções de pessoas, grupos, pesquisadores ou do próprio pesquisador que poderão estabelecer os critérios de análise para compreender melhor as relações de performance mediadas pelas mídias sociais.

\section{Considerações finais}

A performance musical existe na atuação em público ou para um público, que pode ser real, previsto ou virtual. Gravações tornaram a performance musical um produto que pode ser registrado e transmitido pela mídia que ao longo do século XX utilizou cinema, rádio, televisão, vídeo e internet como meios de comunicação. As ferramentas disponíveis de produção e divulgação de vídeos permitem que performer tenha recursos para elaborar, produzir, editar e divulgar seus projetos de performance musical.

A elaboração de projetos no contexto da internet exige três habilidades totalmente distintas para o desenvolvimento de trabalhos: conteúdo, produção e comunicação. Torna-se importante gerar um conteúdo musical que apresente uma informação específica para o público que irá visualizar a produção musical. No entanto, ser um expert ou virtuoso não assegura bons resultados sem uma produção audiovisual com padrões mínimos de qualidade de som e imagem. Além de um conteúdo de qualidade e uma boa produção ainda faz-se necessário a comunicação e divulgação pelas redes sociais, de acordo com as características de linguagem de cada uma das plataformas.

O conteúdo musical é a parte da performance que músicos estavam preparados para realizar em eventos presenciais. A preparação de um recital, um concerto, um festival que estivesse vinculado a um ritual de performance ao vivo. A preparação focada no repertório e no contexto acústico do local de realização do evento, com ensaios e passagens de som necessárias para o músico ficar preparado para a performance no ambiente físico da apresentação.

A produção de vídeo requer um conhecimento totalmente distinto, pois está relacionado com a seleção de imagens e captação do áudio. A pré-produção verifica o local, equipamento, configurações de áudio, configurações de vídeo, cenário, figurino, 
iluminação e maquiagem. A produção inclui a gravação em áudio e vídeo, iluminação, foco, e controle das tomadas de gravação. A pós-produção realiza o download dos arquivos, seleção de tomadas, layout do vídeo, informações sobre a gravação, edição, imagens de divulgação e renderização do vídeo final.

O processo de divulgação em mídias sociais inclui a escolha de plataformas, a definição de identidade verbal principal e das linguagens verbais de cada plataforma, upload de arquivos, conversão de arquivos para os formatos desejados, upload de arquivos, upload de texto e publicação nas plataformas em dias e horários previamente planejados, interação com hashtags para divulgação e respostas online que criem o maior envolvimento com uma comunidade virtual.

Após a realização do projeto e divulgação nas mídias sociais, o processo de tocar com diversos instrumentos foi mantido como prática diária. Foram selecionados sete instrumentos e dez boquilhas que estão sendo utilizados em rodízio. O hábito de adaptação a novas percepções de sonoridade e afinação estabelece um desafio diário de redescoberta de possibilidades. Existem várias vozes nos diversos instrumentos e a performance com cada configuração permite evidenciar aspectos sonoros distintos e explorar elementos enriquecedores para a expressividade musical.

O grande desafio deste projeto foi transformar um protocolo de pesquisa, tradicionalmente baseado em processos impessoais, em um projeto público. A dinâmica da interação por meio das mídias sociais exige pessoalidade para tornar o processo humanizado. A colocação do pesquisador como sujeito da própria pesquisa pública apresenta uma nova realidade de interações e formação de conhecimento realizada em ambientes virtuais. Novas realidades exigem a adaptação e transformação do conhecimento e a pandemia exigiu uma convivência mediada pelos recursos digitais. A experiência da pandemia ofereceu oportunidades para reflexão sobre a própria realidade e nesta pesquisa a realidade estava acompanhada de vários instrumentos com suas vozes particulares que mostraram diversos pontos de vista para a mesma música e para um mesmo clarinetista. 


\section{Referências}

ALMEIDA, Andre; GEORGE, David; SMITH, John; WOLFE, Joe. The clarinet: How blowing pressure, lip force, lip position and reed "hardness" affect pitch, sound level, and spectrum. The Journal of the Acoustical Society of America, v. 134, 2247, 2013. https://asa.scitation.org/doi/10.1121/1.4816538.

FREIRE, Ricardo J. D. Utilização da série harmônica e da série sub-harmônica como recurso pedagógico em aulas de percepção musical e solfejo. In: SIMCAM - Simpósio Internacional de Cognição e Artes Musicais, 2016, Porto Alegre- RS. Anais do SIMCAM XII. Curitiba-PR: Associação Brasileira de Cognição Musical, 2016 . v. 1, p. 311-319. https://abcogmus.org/2020/09/14/anais-do-12o-simposio-internacional-de-cognicao-e-artesmusicais/.

FREIRE, Ricardo J. D. Como será que eu afino? A relação entre sistemas de afinação e parâmetros de afinação na performance musical. Música Hodie, v. 16, p. 133-144, 2016. https://www.revistas.ufg.br/musica/article/view/45333.

FREIRE, Ricardo J. D. Relações de afinação na produção de notas resultantes de acordo com os sistemas de Afinação Igual, Pitagórico e Justo. Percepta - Revista de Cognição Musical, v. 4, p. 79-94, 2017. https://www.abcogmus.org/journals/index.php/percepta/article/view/36.

GRELLIER, Claire. Studying Clarinet in France: a Guide for American Clarinet Students Who Wish to Study in French Music Institutions. Ensaio de Doutorado (Doutorado em Música) School of Music, University of Miami, Miami-FL, 2020.

HOLOMAN, Kern. The Paris Conservatoire in the Nineteenth Century. Oxford Handbooks Online, https://www.oxfordhandbooks.com em 15 de novembro de 2020. Oxford University Press, 2018.

KOVÁCS, Bela. Hommages. Leverkusen, Germany: Edition Darok, 1994.

LAWSON, Colin. The Cambridge Companion to the Clarinet. Cambridge: Cambridge University Press, 1995

RAY, Sonia. Pedagogia da Performance Musical. Goiânia: Editora Espaço Acadêmico, 2019. 
